\title{
Preface
}

\section{The nutritional value and health benefits of pulses in relation to obesity, diabetes, heart disease and cancer}

Pulses are the edible seeds of the plants in the legume family and include dry bean, pea, lentil, chickpea and faba beans. As described in the FAO definition ${ }^{1}$, the term "pulses" excludes legumes used for oil extraction (soybean, peanut) and those harvested green for food (green pea, green bean); the latter being classified as vegetables. Pulses and pulse ingredients, including whole pulses, split pulses, pulse flours and pulse fractions (protein, starch, fibre, bioactive components) offer an abundance of nutritional advantages relevant to chronic disease and health issues of global concern. In comparison to oilseeds like soybean, canola and flax, pulses are very low in $\mathrm{fat}^{2}$. Similar to whole grain cereals like wheat, barley, and oats, pulses contain high amounts of complex carbohydrates including soluble and insoluble fibre ${ }^{3}$. Other complex carbohydrates present in pulses are resistant and slowly digestible starch as well as oligosaccharides ${ }^{3,4}$. Pulses are somewhat unique in comparison to other plant foods in that they contain higher proportions of protein. In fact, the protein content of pulses ranges from $17-30 \%$ of dry weight which is typically twice the amount found in cereals ${ }^{5}$ although not all essential amino acids are present. Pulses are also nutrient dense, providing substantial amounts of vitamins and minerals in a relatively low amount of calories. Some key minerals in pulses include iron, zinc, selenium, phosphorous and potassium. Pulses are also particularly abundant in B vitamins including folate, thiamin, niacin ${ }^{6}$ and contain a range of potentially bioactive nutrients which might improve glycemic control, protect against hypercholesterolemia, cancer and type 2 diabetes $^{7}$.

The nutritional benefits of pulses are well recognized by governments and health organizations globally and are recommended as part of healthy eating. Pulses are included as foods to eat more often in Health Canada's Eating Well with Canada's Food Guide, the MyPlate system of the United States Department of Agriculture (USDA), the Eatwell Plate of the Food Standards Agency in the UK and Nutrition Australia's Healthy Living Pyramid. ${ }^{8-11}$ Health organizations focused on diabetes, heart disease and cancer promote pulse consumption as part of healthy diets for reducing the risk of these chronic diseases. The 2010 Dietary Guidelines for Americans recommend dry beans as a food to increase in the diet. Current consumption of pulses in North America is low compared to traditional markets like India and Spain with only $7.9 \%$ of adults in the U.S. consuming dry beans and peas on any given day. ${ }^{12}$ Interestingly, per capita consumption in traditional markets has been declining in recent years and this has been paralleled by an increase in the same health and chronic disease issues facing North America. ${ }^{13}$ Mitchell et $a l .{ }^{12}$ reported that consumption of approximately $1 / 2$ cup dry beans or peas per day resulted in higher intakes of fiber, protein, folate, zinc, iron, and magnesium with lower intakes of saturated fat and total fat. Tracking nutrient consumption is important to health agencies and analysis of consumer diet surveys provides insights into consumption patterns for a number of food groups. This special issue includes a paper on pulse consumption in Canada based on the Canadian Community Health Survey and demonstrates how a diet high in pulses can provide important nutrients including fibre and folate.

In general, a diet that is high in fibre, low in energy density and glycemic load, and moderate in protein is thought to be particularly important for weight control. ${ }^{14}$ Pulses are high in fibre, contain protein and are well established as a low glycemic index food. ${ }^{15} \mathrm{~A}$ recent review paper $^{16}$ summarized existing research related to pulse consumption, satiety and weight management. To date few published studies have specifically measured the effects of pulses on satiety and appetite. Published short-term (single meal) studies showed reduced hunger and increased satiety 2-4 hours after pulse consumption when controlled for energy. ${ }^{16}$ Longer term interventions ranging from 3-8 weeks found that pulses have a beneficial effect on weight loss during intentional energy restriction. In this special issue, there are three original papers related to the impact of pulses on short-term satiety, food intake and glycemic response as well as one original paper focused specifically on the effect of long term pulse consumption on weight loss in humans.

Soluble fibre is well known for its positive effects on total and LDL cholesterol which are recognized risk factors for heart disease. Some studies also report benefit of increased vegetable protein consumption in relation to heart disease. ${ }^{17}$ In 2009, a meta-analysis ${ }^{18}$ of 10 randomized controlled human clinical trials evaluating the effects of pulse consumption on cholesterol levels indicated that a pulse-rich diet decreases total and LDL cholesterol. This special issue contains two original papers specifically relevant to this topic including one that looks at the metabolomic effects of beans related to tissue lipid metabolism. 
Pulses contain high amounts of insoluble fibre which has been established to improve colon health. In addition, there are various phytonutrients including antioxidants, found in pulses that may have anti-cancer properties. ${ }^{6}$ Four original papers focused on pulses and their potential benefits in relation to cancer are included in this supplement.

In summary, pulses are very rich in nutrients important for a healthy diet and relevant to chronic disease issues of global significance including obesity, diabetes, heart disease and cancer. In order to increase consumption of pulses however, there is a need for more convenient, tasty pulse-based food products that meet the demands of today's consumer. Increasing the body of strong quality evidence to support future health claims for pulses has the potential to influence consumer demand and food industry interest in developing pulse-based food products.

This special issue of the British Journal of Nutrition was initiated by Pulse Canada, a not-for-profit industry association that represents growers, processors and traders of pulse crops in Canada. Pulse Canada's initiatives are focused on 1) developing new markets for pulses by highlighting the nutrition and environmental benefits of pulses and 2) addressing industry issues with market access and transportation. For more information please visit www.pulsecanada.com. We are grateful to Dr. Carol Ann Patterson of the Pathfinders Research and Management Ltd for acting as managing editor of the supplement and to the 3 guest editors: Dr. Jon Buckley, Dr. Martine Champ and Dr. Carla Taylor for their contributions and time.

Julianne Curran PhD

Director of Nutrition Scientific and Regulatory Affairs Pulse Canada 1212-220 Portage Avenue Winnipeg Manitoba

Canada R3C OA5

email jcurran@pulsecanada.com

doi:10.1017/S0007114512003534

\section{References}

1. FAO (2004) Definition and classification of commodities, 4 Pulses and derived products. http://www.fao.org/es/ faodef/fdef04e.htm\#4.01. Accessed September 2, 2011.

2. U.S. Department of Agriculture, Agricultural Research Service (2010) USDA National Nutrient Database for Standard
Reference, Release 23 Nutrient Data Laboratory Home Page, http://www.ars.usda.gov/ba/bhnrc/ndl

3. Tosh S \& Yada S (2010) Dietary fibres in pulse seeds and fractions: Characterization, functional attributes, and applications. Food Res Intl 43, 450-460.

4. Hoover R, Hughes T, Chung HJ, et al. (2010) Composition, molecular structure, properties, and modification of pulse starches: a review. Food Res Intl 43, 399-413.

5. Boye J, Zare F \& Pletch A (2010) Pulse proteins: Processing, characterization, functional properties and applications in food and feed. Food Res Intl 43, 414-431.

6. Campos-Vega R, Loarca-Pina G \& Oomah BD (2010) Minor components of pulses and their potential impact on human. Food Res Intl 43, 461-482.

7. Kalogeropoulos N, Chiou A, Ioannou M, et al. (2010) Nutritional evaluation and bioactive microconstituents (phytosterols, tocopherols, polyphenols, triterpenic acids) in cooked dry legumes usually consumed in Mediterranean countries. Food Chemistry 121, 682-690.

8. Health Canada (2007) Eating Well with Canada's Food Guide. Accessed: http://www.hc-sc.gc.ca/fn-an/alt_formats/ hpfb-dgpsa/pdf/food-guide-aliment/view_eatwell_vue_bien mang-eng.pdf

9. United States Department of Agriculture (2011) MyPlate. Accessed: http://www.choosemyplate.gov/

10. Food Standards Agency. Department of Health in association with the Welsh Assembly Government, the Scottish Government and the Food Standards Agency in Northern Ireland. The Eatwell Plate.

11. Australian Nutrition Foundation Inc (Nutrition Australia). The Healthy Living Pyramid. Accessed: http://www.nutri tionaustralia.org/national/product/healthy-living-pyramid

12. Mitchell D, Lawrence F, Hartman T, et al. (2009) Consumption of dry beans, peas, and lentils could improve diet quality in the US population. J Am Diet Assoc 109, 909-913.

13. World Health Organization. Accessed: http://www.who.int/ gho/countries/en/index.html

14. Albete I, Astrup A, Martinez JA, et al. (2010) Obesity and the metabolic syndrome: role of different dietary macronutrient distribution patterns and specific nutritional components on weight loss and maintenance. Nutr Rev 68, 214-231.

15. Foster-Powell K, Holt SH \& Brand-Miller JC (2002) International table of glycemic index and glycemic load values: 2002. Am J Clin Nutr 76, 5-56.

16. McCrory M, Hamaker B, Lovejoy J, et al. (2010) Pulse Consumption, Satiety and Weight Management. Advances in Nutrition 1, 17-30.

17. Halton TL, Willett WC, Liu S, et al. (2006) Low-carbohydratediet score and the risk of coronary heart disease in women. N Engl J Med 355, 1991-2002.

18. Bazzano LA, Thompson AM, Tees MT, et al. (2011) Non-soy legume consumption lowers cholesterol levels: a meta-analysis of randomized controlled trials. Nutr Metab Cardiovasc Dis 21, 94-103. 